Wright State University

CORE Scholar

Physics Faculty Publications

Physics

4-1-2007

\title{
Electron Irradiation Induced Deep Centers in Hydrothermally Grown ZnO
}

\author{
Z-Q. Fang \\ B. Claflin \\ David C. Look \\ Wright State University - Main Campus, david.look@wright.edu \\ Gary C. Farlow \\ Wright State University - Main Campus, gary.farlow@wright.edu
}

Follow this and additional works at: https://corescholar.libraries.wright.edu/physics

Part of the Physics Commons

\section{Repository Citation}

Fang, Z., Claflin, B., Look, D. C., \& Farlow, G. C. (2007). Electron Irradiation Induced Deep Centers in Hydrothermally Grown ZnO. Journal of Applied Physics, 101 (8), 86106.

https://corescholar.libraries.wright.edu/physics/158

This Article is brought to you for free and open access by the Physics at CORE Scholar. It has been accepted for inclusion in Physics Faculty Publications by an authorized administrator of CORE Scholar. For more information, please contact library-corescholar@wright.edu. 


\title{
Electron irradiation induced deep centers in hydrothermally grown ZnO
}

\author{
Z.-Q. Fang, ${ }^{\text {a) }}$ B. Claflin, and D. C. Look \\ Semiconductor Research Center, Wright State University, Dayton, Ohio 45435 \\ and Materials and Manufacturing Directorate, Air Force Research Laboratory, \\ Wright Patterson AFB, Ohio 45435 \\ G. C. Farlow \\ Physics Department, Wright State University, Dayton, Ohio 45433
}

(Received 4 January 2007; accepted 21 February 2007; published online 25 April 2007)

\begin{abstract}
An $n$-type hydrothermally grown $\mathrm{ZnO}$ sample becomes semi-insulating $\left(\rho \sim 10^{8} \Omega \mathrm{cm}\right)$ after $1-\mathrm{MeV}$ electron-irradiation. Deep traps produced by the irradiation were studied by thermally stimulated current spectroscopy. The dominant trap in the as-grown sample has an activation energy of $0.24 \mathrm{eV}$ and is possibly related to $\mathrm{Li}_{\mathrm{Zn}}$ acceptors. However, the electron irradiation introduces a new trap with an activation energy of $0.15 \mathrm{eV}$, and other traps of energy 0.30 and $0.80 \mathrm{eV}$, respectively. From a comparison of these results with positron annihilation experiments and density functional theory, we conclude that the $0.15-\mathrm{eV}$ trap may be related to $\mathrm{V}_{\mathrm{Zn}}$. () 2007 American Institute of Physics. [DOI: $10.1063 / 1.2719003$ ]
\end{abstract}

Large $\mathrm{ZnO}$ crystals can presently be grown from the vapor phase (VP), ${ }^{1}$ melt (MLT), ${ }^{2}$ or water solution [hydrothermal (HYD)]. ${ }^{3}$ Unintentionally doped VP and MLT ZnO samples nearly always have low resistivities $(\sim 1 \Omega \mathrm{cm})$, due to high concentrations $\left(10^{16}-10^{17} \mathrm{~cm}^{-3}\right)$ of uncompensated shallow donors. In contrast, HYD samples typically have much higher resistivities $(\sim 200-1000 \Omega \mathrm{cm})$, because the shallow donors are fully compensated by acceptors (e.g., Li) present in the mineralizer, ${ }^{3}$ and the electrical properties are thus controlled by deep donors. The deep centers in VP and MLT ZnO samples have been previously studied by deep level transient spectroscopy (DLTS) ${ }^{4,5}$ Both materials contained two prominent defects: $E 1$ at $E_{C}-0.12 \mathrm{eV}$ and $E 3$ at $E_{C}-0.29 \mathrm{eV}$. In VP $\mathrm{ZnO}, E 1$ is the primary defect, while in MLT $\mathrm{ZnO}, E 3$ dominates. An electron trap at $E_{C}-0.3 \mathrm{eV}$ was also found in early HYD $\mathrm{ZnO}$ single crystals (with net donor density in the range $2-8 \times 10^{14} \mathrm{~cm}^{-3}$ ) by DLTS studies. ${ }^{6}$ The $0.3-\mathrm{eV}$ defect is evidently a native donor and has been attributed to oxygen vacancies $\left(\mathrm{V}_{\mathrm{O}}\right){ }^{4,6}$ High-energy $(1.8 \mathrm{MeV})$ proton irradiation can induce point defects in VP $\mathrm{ZnO}$ samples, albeit with very low production rates, and in that case DLTS finds two defects, $E p 1$ at $E_{C}-0.54 \mathrm{eV}$ and $E p 2$ at $E_{C}-0.78 \mathrm{eV}{ }^{7}$ High-energy $(>1.6 \mathrm{MeV})$ electron irradiation can also create point-defect related acceptors and donors in $\mathrm{VP} \mathrm{ZnO}$, with more damage if the beam is directed toward the $\mathrm{Zn}$ face than the $\mathrm{O}$ face. ${ }^{8}$ However, unlike the case in VP or MLT ZnO, we have found that $1-\mathrm{MeV}$ electron irradiation in $\mathrm{HYD} \mathrm{ZnO}$ can easily produce semi-insulating (SI) material, with resistivity $>10^{8} \Omega \mathrm{cm} .{ }^{9}$ Because such high-resistivity samples cannot be studied by DLTS, we have instead applied thermally stimulated current (TSC) spectroscopy, which has earlier been successfully used to study various other SI wide-band gap materials, such as carbon-doped GaN (Ref. 10) and high-purity 4H-SiC. ${ }^{11}$

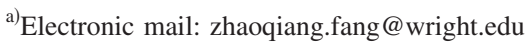

The HYD $\mathrm{ZnO}$ sample used in this study was a $5 \mathrm{~mm}$ $\times 5 \mathrm{~mm} \times 0.5 \mathrm{~mm} c$-axis-oriented plate cut from a larger $10 \mathrm{~mm} \times 10 \mathrm{~mm}$ plate supplied by Tokyo Denpa. ${ }^{12}$ Hall-effect measurements were performed at room temperature, with Ohmic contacts prepared by soldering indium dots onto the corners of the sample. The electrical properties included: resistivity of $210 \Omega \mathrm{cm}$, carrier concentration of $1.6 \times 10^{14} \mathrm{~cm}^{-3}$, and electron mobility of $185 \mathrm{~cm}^{2} / \mathrm{V} \mathrm{s}$. Fitting of the temperature-dependent mobility and carrier concentration was accomplished with the following parameters: donor energies $E_{D 1}=48 \mathrm{meV}, E_{D 2}=300 \mathrm{meV}$; donor concentrations $N_{D 1}=1.5 \times 10^{16} \mathrm{~cm}^{-3}, N_{D 2}=1.0 \times 10^{15} \mathrm{~cm}^{-3}$; and acceptor concentration $N_{A}=1.49 \times 10^{16} \mathrm{~cm}^{-3}$. Note that the donors are rather closely compensated by the acceptors.

Electron irradiation (EI) was carried out at room temperature using $1-\mathrm{MeV}$ electrons produced by a Van de Graaff accelerator. An electron fluence of $2 \times 10^{16} \mathrm{~cm}^{-2}$ was used in two consecutive irradiations giving a total dose of $4 \times 10^{16} \mathrm{~cm}^{-2}$. Recent molecular dynamics simulations have determined 300-K displacement threshold energies of 44 and $34 \mathrm{eV}$ for $\mathrm{O}$ and $\mathrm{Zn}$, respectively. ${ }^{13}$ We can then use the McKinley-Feshbach formula to calculate $\mathrm{O}$ and $\mathrm{Zn}$ Frenkelpair production rates of 0.37 and $0.61 \mathrm{~cm}^{-1}$, respectively, resulting from bombardment by $1-\mathrm{MeV}$ electrons. For a total electron fluence of $4 \times 10^{16} \mathrm{~cm}^{-2}$, the expected concentrations of $\mathrm{O}$ vacancies and $\mathrm{Zn}$ vacancies would thus be $1.5 \times 10^{16} \mathrm{~cm}^{-3}$ and $2.4 \times 10^{16} \mathrm{~cm}^{-3}$, respectively. Even though the actual concentrations would likely be smaller, because of defect annihilation processes, still it is known that some $\mathrm{Zn}$ vacancies still survive (Ref. 15) and are stable to about $300{ }^{\circ} \mathrm{C}$ (Ref. 8). Even if only $10 \%$ were to survive, that would still produce an additional acceptor concentration of about $2 \times 10^{15} \mathrm{~cm}^{-3}$, which would be enough to complete the compensation of both the 48- and $300-\mathrm{meV}$ donors and produce highly resistive material.

TSC spectroscopy involves filling electron and hole traps by illumination at low temperature and then warming 


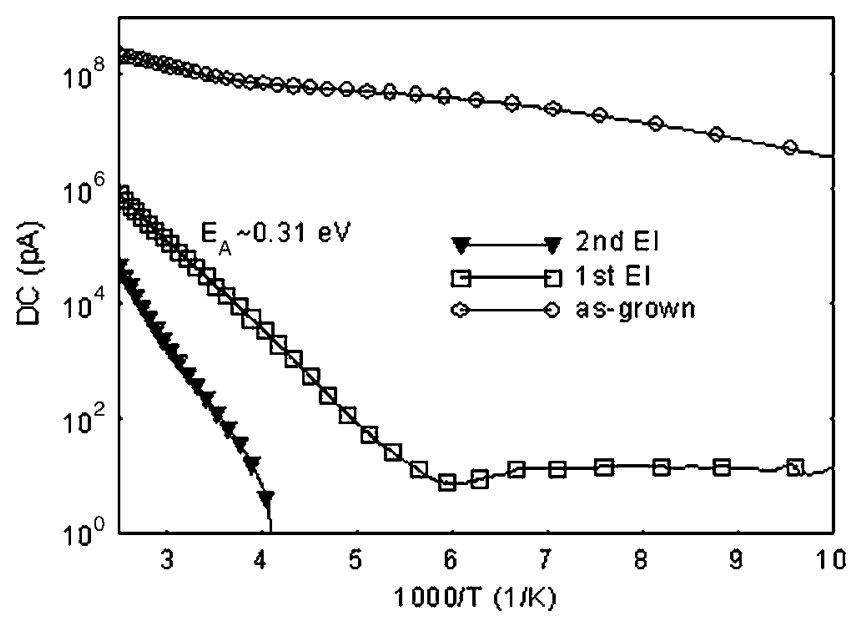

FIG. 1. Arrhenius plots of DC for the $\mathrm{ZnO}$ sample before and after irradiation. The curves were obtained while cooling the sample at a rate $\beta=0.3 \mathrm{~K} / \mathrm{s}$ under a bias $V_{b}=1 \mathrm{~V}$.

the sample in the dark while recording the current due to the thermal emission of carriers from the traps. To keep the initial conditions the same, the sample was always cooled from 400 to $83 \mathrm{~K}$ in the dark. During cooling, the dark current (DC) was measured as a function of temperature. The traps were filled at $83 \mathrm{~K}$ by illumination with 400 -nm (near-band gap) light, produced by a 15-W halogen lamp and a bandpass filter. The photocurrent (PC) response was recorded at $83 \mathrm{~K}$ during a 5-min illumination period and the decay of persistent photocurrent was then recorded for $30 \mathrm{~s}$ after switching the light off. After that, the TSC spectrum was measured during warming at a heating rate of $\beta=0.3 \mathrm{~K} / \mathrm{s}$ under a bias of 0.1 or $1 \mathrm{~V}$, depending on the resistivity of the sample. From the TSC peak temperature $T_{m}$ for a given trap, the approximate activation energy can be determined from the relation $^{14}$

$$
E_{T}=k T_{m} \ln \left(T_{m}^{4} / \beta\right) .
$$

Note that TSC characterization by itself cannot tell whether a peak is due to an electron trap or a hole trap. However, based on a comparison of the measured activation energies with those determined in earlier samples by DLTS or other means, we can speculate on the origins of the TSC traps observed in our as-grown and irradiated HYD $\mathrm{ZnO}$ samples.

An Arrhenius plot of DC measured upon cooling at $V_{b}=1 \mathrm{~V}$ for the HYD $\mathrm{ZnO}$ sample before and after the first and second EIs is presented in Fig. 1. Before the EI (top curve), the sample shows mid-resistive behavior, with the conductivity controlled by relatively shallow donors. After the first EI (middle curve), the resistivity greatly increases and has a conductivity activation energy of about $0.3 \mathrm{eV}$, and after the second EI (bottom curve), the sample becomes semi-insulting. In total, the DC at $400 \mathrm{~K}$ is reduced by nearly four orders of magnitude. Positron annihilation spectroscopy has been used previously to study point defects introduced in VP $\mathrm{ZnO}$ by $2-\mathrm{MeV}$ EI. The results show that Zn-vacancy acceptors are important in the electrical compensation. ${ }^{15}$ Thus, it is reasonable to conclude that the significant reduc-

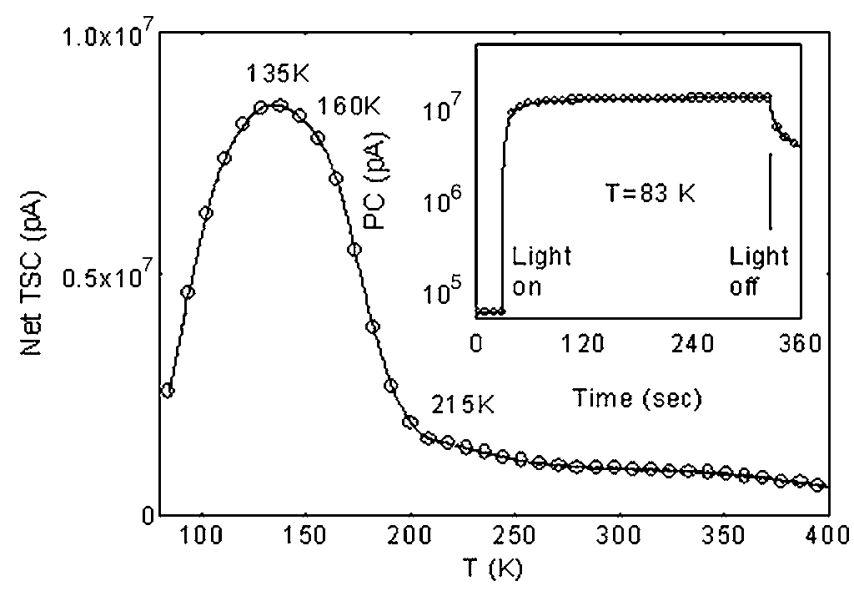

FIG. 2. Net TSC spectrum (i.e., TSC-DC) for the as-grown sample following 400-nm illumination at $83 \mathrm{~K}$. The bias and heating rate were $V_{b}$ $=0.1 \mathrm{~V}$ and $\beta=0.3 \mathrm{~K} / \mathrm{s}$, respectively. The inset displays the time dependence of the $\mathrm{PC}$ at $83 \mathrm{~K}$.

tion in conductivity of $\mathrm{HYD} \mathrm{ZnO}$ after electron irradiation is due to the introduction of zinc vacancies.

The net TSC spectrum (i.e., TSC-DC) for the as-grown sample (before EI) is shown in Fig. 2. The PC response measured at $83 \mathrm{~K}$ is shown in the inset of the figure. The response consists of: (i) an initial transient, related to trapfilling processes; (ii) a saturation region, with equal rates of carrier emission and capture; and (iii) a decay or persistent photocurrent, related to the thermal emission of carriers from shallow traps at $83 \mathrm{~K}$. The TSC spectrum is dominated by a broad peak centered at $135 \mathrm{~K}$, but also includes a shoulder at $160 \mathrm{~K}$ and a small peak at $215 \mathrm{~K}$. Using Eq. (1), the activation energies are estimated to be $0.24 \mathrm{eV}$ for the $135-\mathrm{K}$ peak and $0.30 \mathrm{eV}$ for the $160-\mathrm{K}$ shoulder. Recently, a Li-related acceptor state with a thermal activation energy of approximately $0.26 \mathrm{eV}$ in a similar Tokyo Denpa $\mathrm{ZnO}$ sample was determined to play a key role in electron trapping phenomena. ${ }^{16}$ Thus, we tentatively assign the $0.24-\mathrm{eV}$ center to $\mathrm{Li}_{\mathrm{Zn}}$ acceptors. Also, the weak $0.30-\mathrm{eV}$ center in the asgrown sample could possibly be related to oxygen vacancies, as reported in earlier DLTS studies on VP and HYD $\mathrm{ZnO}$ samples. ${ }^{4,6}$

It is difficult to directly compare the magnitudes of the TSC spectra of the as-grown and irradiated samples, because the TSC signal is proportional to the dominant carrier lifetime in each case and the carrier lifetimes are unknown. However, the PC is also proportional to carrier lifetime, and thus a rough normalization can be effected by dividing the TSC signal by the PC signal at $83 \mathrm{~K}$. Such a normalization should be reasonably accurate for at least the low temperature traps. In Fig. 3 is displayed the net, normalized TSC curves $\{$ i.e., $[\mathrm{TSC}-\mathrm{DC}] /[\mathrm{PC}(83 \mathrm{~K})]\}$ for the as-grown and irradiated samples. The traps in the as-grown sample have been discussed above. After the first EI, traps at 94 and 375 $\mathrm{K}$ are clearly observed and the use of Eq. (1) gives energies of 0.16 and $0.80 \mathrm{eV}$, respectively, for these centers. A more accurate Arrhenius analysis (not shown) of the 94-K trap gives an energy of $0.15 \mathrm{eV}$, in agreement with the more approximate value mentioned earlier. In an optical-DLTS study on VP $\mathrm{ZnO}$, a hole trap located at $0.16 \mathrm{eV}$ above the 


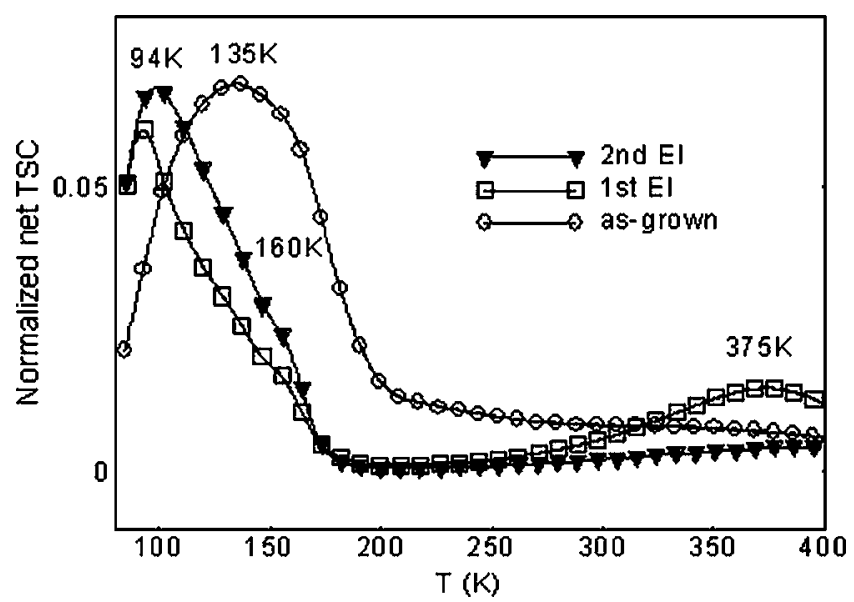

FIG. 3. Net and normalized TSC spectra \{i.e., [TSC-DC]/[PC (83 K)]\} for the as-grown and irradiated samples following $400-\mathrm{nm}$ illumination at $83 \mathrm{~K}$. The bias and heating rate were $V_{b}=1 \mathrm{~V}$ and $\beta=0.3 \mathrm{~K} / \mathrm{s}$, respectively.

valence band edge was found to be introduced by $100-\mathrm{keV}$ proton implantation. ${ }^{17}$ Thus, we believe that the $0.15-\mathrm{eV}$ center, introduced by electron irradiation in HYD $\mathrm{ZnO}$, may also be a hole trap. Since electron irradiation is known to produce stable $\mathrm{Zn}$ vacancies, ${ }^{15}$ and since the $\mathrm{V}_{\mathrm{Zn}}(0 /-)$ transition energy has been determined from density functional theory to be about $0.11 \mathrm{eV},{ }^{18}$ it is possible that this trap is $\mathrm{V}_{\mathrm{Zn}}$ related.

The feature at $135 \mathrm{~K}(0.24 \mathrm{eV})$, which may be related to the acceptor $\mathrm{Li}_{\mathrm{Zn}}$, is dominant in the as-grown sample. On the other hand, the features at $94 \mathrm{~K}(0.16 \mathrm{eV}), 160 \mathrm{~K}(0.30$ $\mathrm{eV})$, and $375 \mathrm{~K}(0.80 \mathrm{eV})$, are likely related to point defects. The 160-K feature has the same energy as that of a trap earlier assigned to $\mathrm{O}$ vacancies. ${ }^{4,6}$ Finally, the $375-\mathrm{K}$ trap has an energy close to that of Ep2 $(0.78 \mathrm{eV})$, introduced in VP $\mathrm{ZnO}$ by proton-bombardment. ${ }^{7}$

In summary, thermally stimulated current spectroscopy has been used to investigate the effects of $1-\mathrm{MeV}$ electron irradiation on a $\mathrm{ZnO}$ sample grown by the hydrothermal method. A dose of $4 \times 10^{16} \mathrm{~cm}^{-2}$ increases the resistivity from about $10^{2}$ to $10^{8} \Omega \mathrm{cm}$, likely due to the introduction of zinc vacancies. Before irradiation, a trap at $0.24 \mathrm{eV}$ dominates the TSC spectrum, and it is probably related to $\mathrm{Li}_{\mathrm{Zn}}$, known to be a major residual impurity in hydrothermal $\mathrm{ZnO}$. Irradiation introduces strong traps at 0.15 and $0.80 \mathrm{eV}$. The former is possibly related to the $\mathrm{Zn}$ vacancy and the latter is reminiscent of Ep2, reported in 1.8-MeV proton-bombarded vapor-phase $\mathrm{ZnO}$. An $0.30-\mathrm{eV}$ trap, possibly related to the oxygen vacancy, can be observed in both as-grown and irradiated $\mathrm{ZnO}$.

The authors wish to thank T. A. Cooper for the Halleffect measurements and N. Giles for helpful discussions. Support was provided by ARO Grant No. W911NF-05-C0024 (M. Gerhold), NSF Grant No. DMR0513968 (L. Hess), SVTA Subcontract No. W911NF-06-C-0015 (A. Osinsky), SMI Subcontract No. SMI41471-010605-01 (G. Tompa), AFOSR Grant No. F49620-03-1-0197 (K. Reinhardt), and AFRL Contract No. FA8650-06-D-5401 (D. Silversmith).

${ }^{1}$ D. C. Look, D. C. Reynolds, J. R. Sizelove, R. L. Jones, C. W. Litton, G. Cantwell, and W. C. Harsch, Solid State Commun. 105, 399 (1998).

${ }^{2}$ J. Nause and B. Nemeth, Semicond. Sci. Technol. 20, S45 (2005).

${ }^{3}$ K. Maeda, M. Sato, I. Niikura, and T. Fukuda, Semicond. Sci. Technol. 20, S49 (2005).

${ }^{4}$ F. D. Auret, S. A. Goodman, M. J. Legodi, W. E. Meyer, and D. C. Look, Appl. Phys. Lett. 80, 1340 (2002).

${ }^{5}$ H. von Wenckstern, R. Pickenhain, H. Schmidt, M. Brandt, G. Biehne, M. Lorenz, M. Grundmann, and G. Brauer, Appl. Phys. Lett. 89, 092122 (2006).

${ }^{6}$ J. C. Simpson and J. F. Cordaro, J. Appl. Phys. 63, 1781 (1988).

${ }^{7}$ F. D. Auret, S. A. Goodman, M. Hayes, M. J. Legodi, H. A. van Laarhoven, and D. C. Look, Appl. Phys. Lett. 79, 3074 (2001).

${ }^{8}$ D. C. Look, D. C. Reynolds, J. W. Hemsky, R. L. Jones, and J. R. Sizelove, Appl. Phys. Lett. 75, 811 (1999).

${ }^{9}$ D. C. Look, Z.-Q. Fang, B. Claflin, and G. C. Farlow (unpublished).

${ }^{10}$ Z.-Q. Fang, D. C. Look, B. Claflin, S. Haffouz, H. Tang, and J. Webb, Phys. Status Solidi C 2, 2757 (2005).

${ }^{11}$ Z.-Q. Fang, B. Claflin, D. C. Look, L. Polenta, and W. C. Mitchel, J. Electron. Mater. 34, 336 (2005).

${ }^{12}$ Tokyo Denpa Co., Ltd., 5-6-11 Chuo, Ohta-ku, Tokyo 143-0024, Japan.

${ }^{13}$ D. C. Look, G. C. Farlow, P. Reunchan, S. Limpijumnong, S. B. Zhang, and K. Nordlund, Phys. Rev. Lett. 95, 225502 (2005).

${ }^{14}$ D. C. Look, Semicond. Semimetals 19, 75 (1983).

${ }^{15}$ F. Tuomisto, K. Saarinen, and D. C. Look, Phys. Status Solidi A 201, 2219 (2004).

${ }^{16}$ O. Lopatiuk, L. Chernyak, A. Osinsky, and J. Q. Xie, Appl. Phys. Lett. 87, 214110 (2005).

${ }^{17}$ A. Y. Polyakov et al., J. Appl. Phys. 94, 2895 (2003).

${ }^{18}$ A. Janotti and C. G. Van de Walle, J. Cryst. Growth 287, 58 (2006). 